\title{
A VARIANT SELECTION MODEL FOR THE PREDICTION OF FCC-TO-BCC TRANSFORMATION TEXTURES
}

\author{
C. S. DA COSTA VIANA*, M. P. BUTRON-GUILLEN and J. J. JONAS \\ McGill University, Department of Metallurgical Engineering 3450 University Street, \\ Montreal, Quebec, Canada H3A $2 A 7$ \\ *Instituto Militar de Engenharia - IME, DE/4, Pça. Gen. Tiburcio, 80 Urca, \\ 22290-270 Rio de Janeiro - RJ, Brazil
}

(Received 14 February 1996)

\begin{abstract}
In the present work, a simple model is described for the prediction of fcc-to-bcc transformation textures. It employs a discrete distribution of orientations and is based on the Kurdjumov-Sachs relationship for the $\gamma$ to- $\alpha$ transformation. An important feature of the model involves the variant selection rule, which assumes that nucleation is favoured according to a slip system based variant selection criterion. Subsequent selective growth involves a transformation work rule based on the Bain strains and the presence of an internal stress field. The transformation texture predicted from an experimental $95 \%$ cold rolled Ni-30wt\%Co alloy texture is compared to experimental martensite textures for both a $\mathrm{Nb}$ microalloyed steel and a Fe-30\% $\mathrm{Ni}$ alloy. The predicted texture displays better agreement with the steel data.
\end{abstract}

KEY WORDS: Transformation textures, Kurdjumov-Sachs relationship, variant selection.

\section{INTRODUCTION}

The inheritance of preferred orientations during the $\gamma$-to- $\alpha$ transformation has been under investigation for a considerable time. As a thorough treatment of this subject would be too lengthy for the present purpose, it is not attempted here. Furthermore, comprehensive reviews of transformation textures have been published recently (Inagaki, 1981; Yutori and Ogawa, 1981; Ray and Jonas, 1990; Ray et al., 1994) covering broad aspects of this topic. These surveys have shown that the formation of ferrite, martensite and bainite follows the general predictions of the Kurdjumov-Sachs (K-S) orientation relationship (Kurdjumov and Sachs, 1930), although frequently only a resticted set of the 24 possible K-S variants is formed during the transformation (King and Bell, 1975; Davies and Bateman, 1981; Honeycombe, 1981).

Evidence has also been presented for the validity of the Nishiyama-Wassermann (Nishiyama, 1936; Wassermann, 1933) relationship, with variant selection, with regard to the transformation of a deformed, cube textured, Fe-30\% Ni alloy (Liu and Bunge, 1991). These authors were able to establish a connection between the selected transformation variants and certain austenite slip directions that were particularly active during the previous rolling deformation.

Several different methods have been used to predict the product textures produced by the $\gamma$-to- $\alpha$ transformation. The texture of the parent (generally the $\gamma$ ) phase has 
either been expressed as a discrete set of ideal orientations (Haslam et al., 1973; Jones and Walker, 1974) or as a continuous ODF. Frequently, the texture of a similar stable fcc material (Kallend and Davies, 1972; Davies, Kallend and Ruberg, 1973; Davies and Bateman, 1981) is used to represent the austenite, as the latter is unstable at room temperature, so that high temperature austenite textures, particularly deformation textures, have not yet been characterized.

The ODF-based methods require analytical operators to transform the parent texture as a whole, be they in the form of rotation operators, as suggested by Roe (1965) and used by Davies, Kallend and Morris (1976), or of generalized correspondence functions, such as the MODF proposed by Sargent (1974) and used by Bateman and Davies (1981) and Davies and Bateman (1981). While mathematically more efficient, the latter methods are unable to deal with the physical nature of the phase transformation on an individual crystal basis. The discrete orientation methods, on the other hand, allow variant selection mechanisms to be introduced on the level of individual parent orientations, making it possible to simulate the peculiarities of texture transformation in different systems. Much of the transformation texture prediction work has been based on the austenite-to-martensite transformation since, being shear based, the nucleation texture is not changed by further preferential diffusive growth. By contrast, austeniteto-ferrite transformation textures are subject to alteration by diffusive growth, both during the transformation and after its completion, a feature that complicates the construction of such models.

In the present work, a model is described which can be used to predict the transformation texture resulting from an fcc-to-bcc phase transformation. The calculation is not affected by the mode of the nucleation mechanism (shear or diffusion) and a discrete orientation approach is employed. An important feature of the simulation is the variant selection rule that is used; it is based on the idea that the internal stresses remaining in the austenite after hot rolling are reduced during transformation. This contribution is intended to pay homage to Prof. $\mathrm{H}$. $\mathrm{Hu}$, an innovative ferrous metallurgist and texture pioneer, who left his mark on the development of materials science in the second half of this century.

\section{THE MODEL}

The present model deals with the textural aspects of the transformation of austenite to either ferrite or cubic martensite. No specific crystallographic mechanism related to either of these reactions is taken into account, only the energies associated with the strains involved in the transformation are considered. It is also assumed that the material is elastic/ideally plastic and that all the austenite grains are in the deformed condition, i.e. unrecrystallized, immediately prior to transformation. According to this view, each grain embedded in the austenite matrix is considered to be subject to the internal stress field that remains in the matrix after the prior rolling deformation. The residual stress is different for each grain and is calculated by subtracting the stress required to induce plasticity in a given crystal (as given by Bishop and Hill, 1951) from the overall stress applied to the polycrystal. The former, $\sigma_{\mathrm{ij}}$, are the stresses necessary to produce plane strain deformation during the last pass of the previous rolling operation; they are obtained from the Bishop and Hill analysis applied to that specific crystal. The latter, $S_{i j}$, are the stresses that represent the global effect of the matrix on the crystal; they are obtained from the Bishop and Hill (1951) polycrystalline yield locus calculated for the parent 
texture and the same strain path.

The residual stress in the matrix that acts on a particular crystal is the negative of the internal stress defined above and is given by the following stress difference: $\sigma_{i j}^{\prime}=\sigma_{i j}-S_{i j}$. These are the stresses that are available to interact with the transformation strains, $\mathrm{d} \varepsilon_{\mathrm{ij}}$. The resulting transformation work, $\Delta \mathrm{W}$, can either aid or hinder the transformation, depending on whether the nucleus being produced is able to relieve or increase the matrix stress, respectively. It aids the transformation if it leads to a decrease in the stored energy of the matrix. For this reason, only positive values of the transformation work will be dealt with in this analysis.

$$
\Delta \mathrm{W}_{\text {transf }}=\sigma_{\mathrm{ij}}^{\prime} \cdot \mathrm{d} \varepsilon_{\mathrm{ij}} \geq 0
$$

Two other important assumptions are made here. First, product nucleation is only considered to occur on the fcc slip systems that were operative during the last rolling pass. Here the systems are deduced using the Bishop and Hill analysis. Considering that the Kurdjumov-Sachs relationship can be expressed as a plus or minus $90^{\circ}$ rotation about a $<112>$ axis common to both the parent and the product, this amounts to deducing these axes from the cross product of the plane normal and slip direction that make up these systems. The $\langle 112\rangle$ axes defined in this way are then used to calculate the orientations of the bcc nuclei. As there are usually 6 or 8 active slip systems in a given fcc grain, this approach leads to the definition of up to 12 or 16 possible bcc nuclei for a given fcc orientation, i.e., less than the 24 variants called for by the $\mathrm{K}$ $\mathrm{S}$ analysis in the absence of variant selection.

In the second step of the calculation, the number of variants is further reduced by taking into account the sign of the transformation work that is applicable to each variant. For this purpose, the transformation strains are taken to be the Bain strains associated with fcc and bcc lattice parameters of $0.361 \mathrm{~nm}$ and $0.286 \mathrm{~nm}$, respectively. These values were chosen so that no volume change takes place on transformation, an approach that simplified the analysis. The orientations of the Bain strains were calculated for each of the $24 \mathrm{~K}-\mathrm{S}$ variants using the geometric characteristics of this relationship.

The evaluation of the transformation work (both in sign and magnitude) is therefore only possible after the selection of the "active" nuclei has been performed. Those which increase the matrix strain, and for which the work is therefore negative, are not permitted to "grow" (and consequently be present in the final transformation texture). By contrast, those that satisfy the transformation work condition (eq.(1)) are retained and considered to constitute the ferrite or martensite texture. Variant selection is thus performed in two stages, and since no specific nucleation mechanism is considered, the model can be applied to any discretized texture that can be considered to be affected by the presence of a stress field.

The discretized orientation distribution of the parent texture - expressed in terms of Bunge-type Euler angles accompanied by their corresponding function heights - yields a set of product orientations that can be converted back into a continuous distribution function and can, in this way, be expressed once again in ODF form. In its present formulation, the model cannot work backwards, using the ferrite or martensite texture as the parent phase. 


\section{EXPERIMENTAL METHOD}

Experimental difficulties have prevented the measurement up to now of the texture of hot rolled austenite immediately before phase transformation, particularly in the case of deformed materials. So, in order to check the validity of the assumptions made in the present model, the texture of a $95 \%$-cold rolled Ni-30wt\%Co alloy was taken as representative of the hot rolled austenite. This material was chosen because it has a stacking fault energy $\left(72 \mathrm{~mJ} / \mathrm{m}^{2}\right)$ similar to that of $\gamma$ iron $\left(75 \mathrm{~mJ} / \mathrm{m}^{2}\right)$, and the above reduction is only slightly greater than those employed on the present ferrous materials (see below). This texture was discretized into individual components specified by their Euler angles $\left(\varphi_{1}, \phi, \varphi_{2}\right.$ in the Bunge notation) and corresponding function heights. This information served as the input to the model program, accompanied by additional data regarding the imposed stress and strain states as well as the transformation strains. The latter items were required for operation of the second variant selection rule. The resulting discrete product orientations were then converted back into an ODF with the aid of a Gaussian function interpolating routine that takes into account the initial function heights and number of nuclei produced from each parent orientation.

Validation of the model was carried out by comparing the transformation texture predicted in this way to two experimental textures determined on: i) an $\mathrm{Fe}-30 \% \mathrm{Ni}$ alloy submitted to a cold rolling reduction of $90 \%$ at room temperature and quenched at - $196^{\circ} \mathrm{C}$ (Bateman and Davies, 1981), and ii) a $0.18 \% \mathrm{C}-1.35 \% \mathrm{Mn}-0.034 \% \mathrm{Nb}$ microalloyed steel. This material was soaked at $1250^{\circ} \mathrm{C}$, hot rolled to a total reduction of $90 \%$, finish rolled at $870^{\circ} \mathrm{C}$ and immediately quenched (Savoie et al., 1993; ButrónGuillén, 1995). In this case, the presence of a martensitic microstructure of the lath type was verified by means of optical metallography.

These materials were chosen because of their different internal microstructures which are indicative of the method of accommodating the transformation strains. According to the literature (Sandvik and Wayman, 1983), martensite laths such as those observed in $\mathrm{Nb}$ microalloyed steels have high internal dislocation densities, in part because of the misfit dislocations that accommodate the lattice mismatch and thus generate the lattice invariant strain. By contrast, the martensite plates that are characteristic of the $\mathrm{Fe}-30 \% \mathrm{Ni}$ alloy are internally twinned; in this case it is the twinning elements that account for the lattice invariant strain associated with the transformation (McDougall and Wayman, 1992).

\section{RESULTS}

The ODF of the $95 \%$-cold rolled Ni-30wt\%Co alloy used to represent the parent phase is illustrated in Figure 1. It can be described in terms of two components: i) a tube of orientations running from $\{011\}<211>$ in the $\varphi_{2}=0^{\circ}$ section to $\{110\}<112>$ in the $\varphi_{2}=45^{\circ}$ section; and ii) a second tube running from $\{112\}<111>$ in the latter section to $\{011\}<211>$ in the $\varphi_{2}=90^{\circ}$ section. (The locations of the above four ideal orientations are illustrated in Figure 2). This is conventionally referred to as the copper orientation tube. This texture was discretized into 228 individual orientations accompanied by their respective function heights; the data were then used to represent the "parent" in the transformation program.

The texture predicted from Figure 1 using the present model is illustrated in Figure 3. By referring to the ideal orientations identified in Figure 2, it can be seen that all 


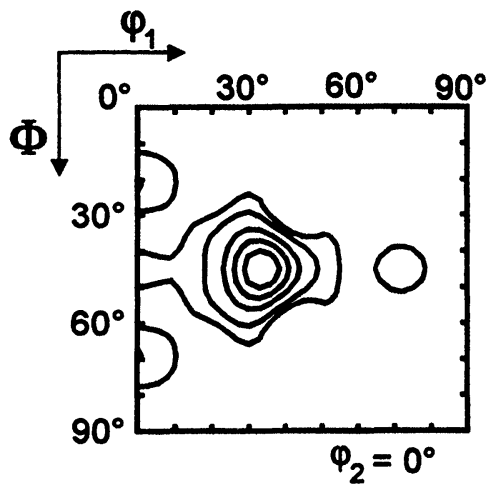

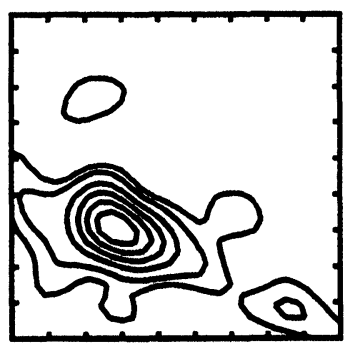

$15^{\circ}$

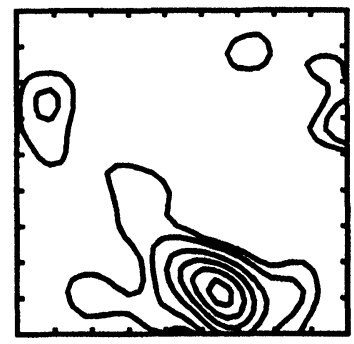

$35^{\circ}$

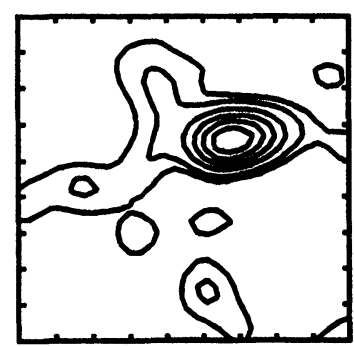

$65^{\circ}$

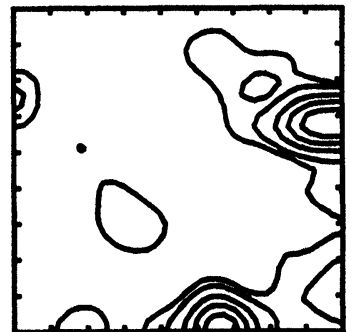

$45^{\circ}$

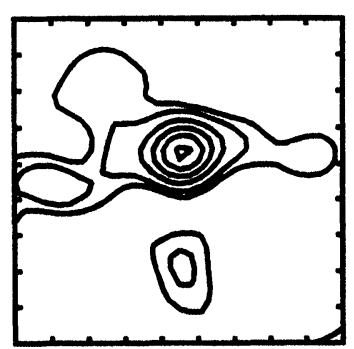

$75^{\circ}$

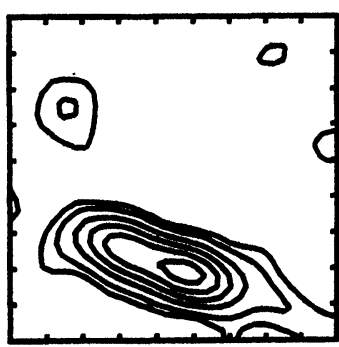

$25^{\circ}$

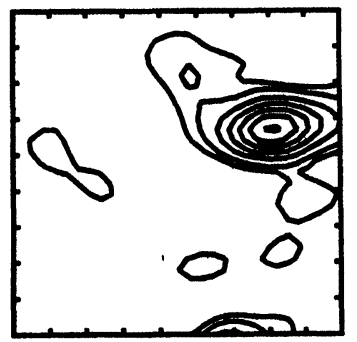

$55^{\circ}$

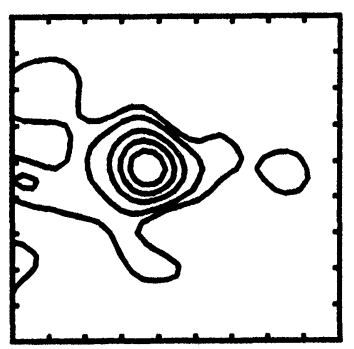

$85^{\circ}$

Figure 1 Experimental texture of the Ni-30\%Co alloy. This was used as the parent fcc material in the simulation. Levels: $1,2,4,6,8,10$, and 12 times random. Maximum Function Height (MFH) $=12.4$.

the main features of a bcc transformation texture are present in this ODF. Of particular

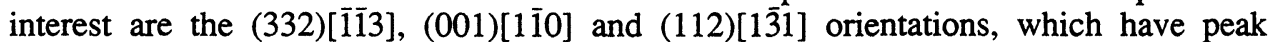
intensities of $5.8,5.2$ and 4.4 , respectively.

The experimental data obtained by Bateman and Davies (1981) on the $\mathrm{Fe}-30 \mathrm{wt} \% \mathrm{Ni}$ alloy are reproduced in Figure 4. The texture of the cold rolled austenite phase is illustrated in Figure $4 \mathrm{a}$ and that of the corresponding bcc martensite in Figure 4b. It can be seen that the fcc textures of Figures 1 and $4 \mathrm{a}$ are in very good agreement, both qualitatively and quantitatively; even the maximum function heights are similar. It is also evident that the maximum function heights of the predicted bcc texture of Figure 3 and the experimental texture of Figure $4 \mathrm{~b}$ are comparable, although there are 

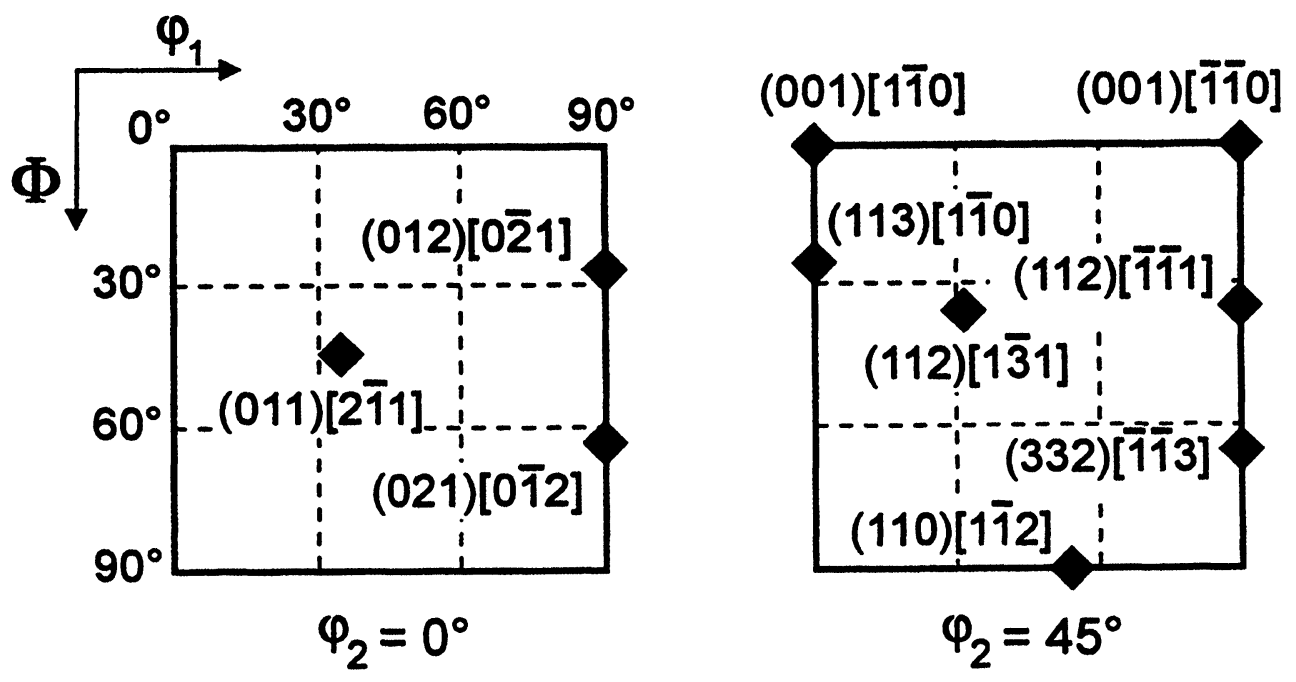

Figure 2 Some important ideal orientations located in the $\varphi_{2}=0^{\circ}$ and $\varphi_{2}=45^{\circ}$ sections of Euler space.

a few important differences. First, the intensity of the (001)[110] orientation is lower in the martensite texture. Second, the function maxima of the two textures occur at different locations in the $\varphi_{2}=45^{\circ}$ sections.

The transformation texture determined on the $\mathrm{Nb}$ microalloyed steel is presented in Figure 5. With a maximum intensity level of 8.4 , this texture can be considered quite strong for a transformed steel. This suggests that the austenite had accumulated considerable strain before its transformation to martensite by quenching. This texture and that of Figure $4 \mathrm{~b}$ are also similar with respect to the orientations present, although the individual intensities differ by factors of $2: 1$ or more.

The ODF cross-sections in Figure 3 and 5 can now be compared and the excellent agreement is readily evident, although the experimental texture is slightly more intense than the simulated one (MFHs of 8.4 and 6.9, respectively). The greatest differences are found in the $\varphi_{2}=45^{\circ}$ section, where the simulated RD-fiber remains closer to the $\phi$-axis and the predicted intensities are lower. The intensities of some important orientations present in the two experimental textures are compared to the predicted intensities in Table 1. These data confirm the general similarities between the two experimental textures and the predicted one and also show that the latter is in better agreement with that of the $\mathrm{Nb}$ steel.

\section{DISCUSSION}

Analysis of the texture of Figure 3 indicates that the present model is capable of predicting the general features of the transformation texture of deformed austenite with considerable accuracy. Unlike the ODF-based methods, which use an analytical operator to rotate the entire orientation distribution, the present technique works at the individual grain level and employs two orientation-dependent rules for variant selection. In this 

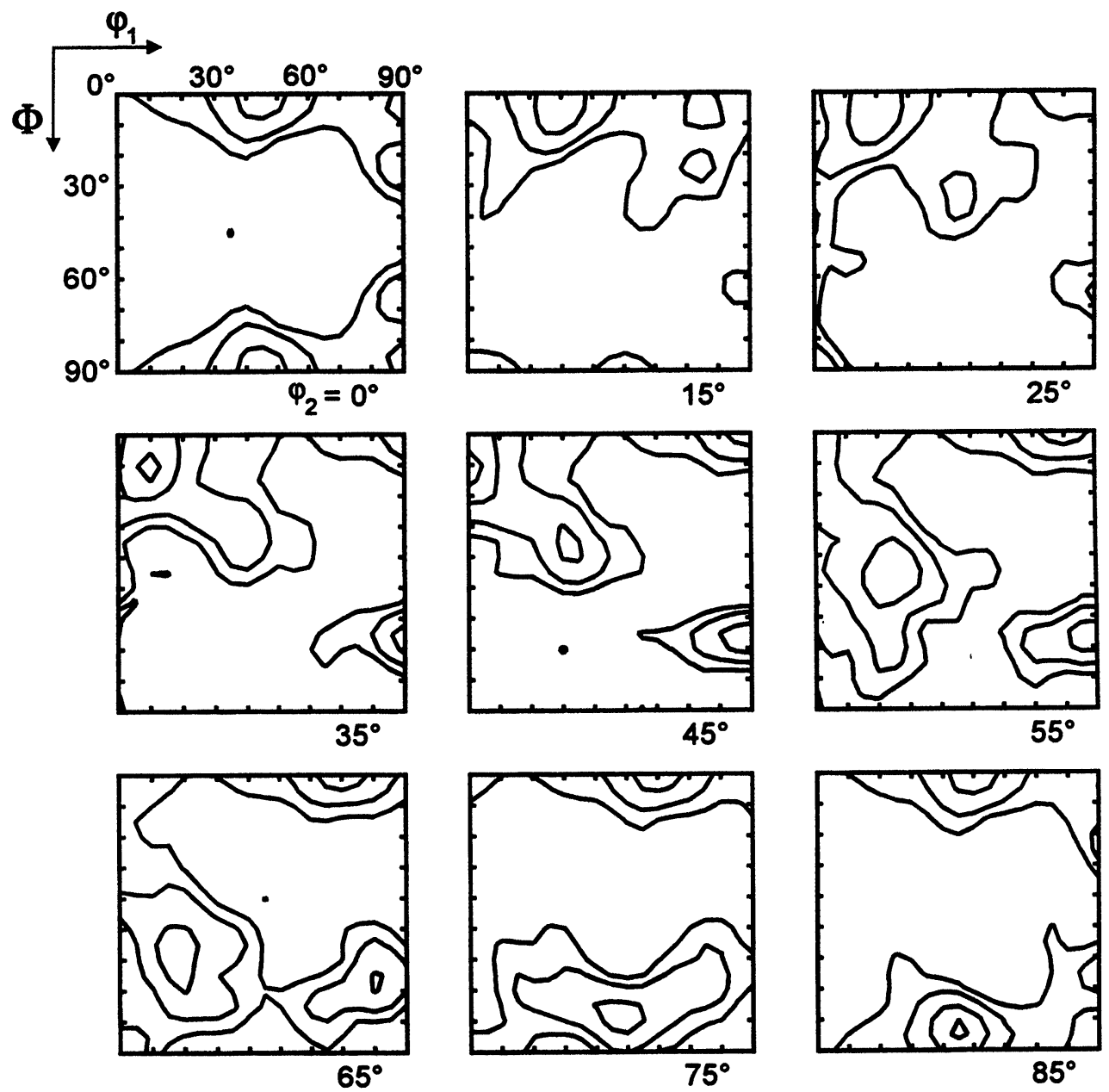

Figure 3 Predicted texture obtained after transformation of the ODF shown in Figure 1. Levels: 1, 2,4 , and 6 times random. $\mathrm{MFH}=6.9$.

way, the physics of the transformation can be represented more accurately, and more realistic assumptions can be made.

Here, a slip system based variant selection assumption was used as a nucleation rule, which eliminated some of the 24 possible product nuclei that satisfy the K-S relationship. A stress-aided transformation concept further reduced the number of allowable product orientations by eliminating the variants whose growth is resisted by the matrix residual stress. This two-step calculation led to the product texture.

Both of these ideas have already been used as variant selection criteria. The former, in support of which experimental evidence was reported by Stone and Thomas (1974) and Liu and Bunge (1991), was put forward by Haslam et al. (1973) and reexamined 


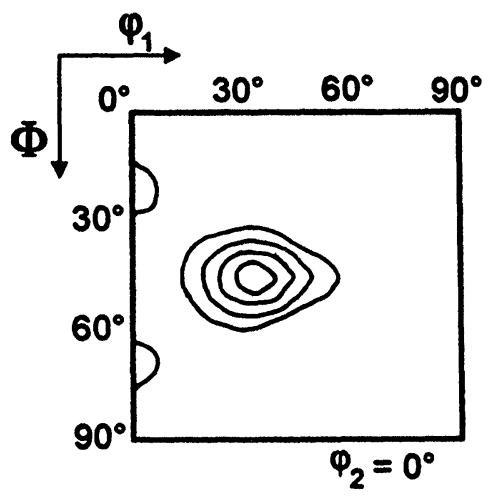

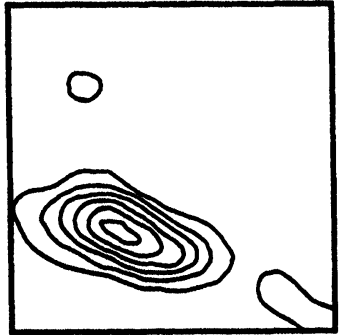

$18.4^{\circ}$

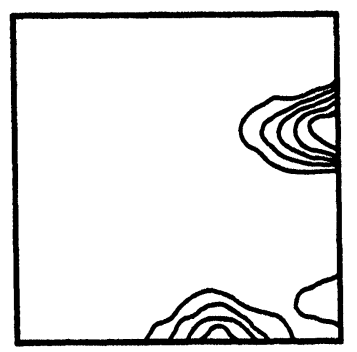

$45^{\circ}$

$31.7^{\circ}$

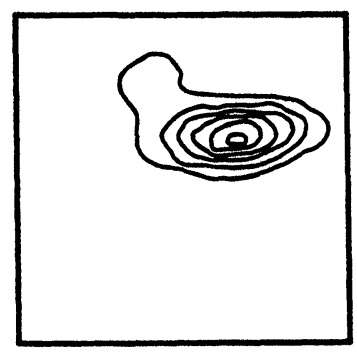

$63.4^{\circ}$

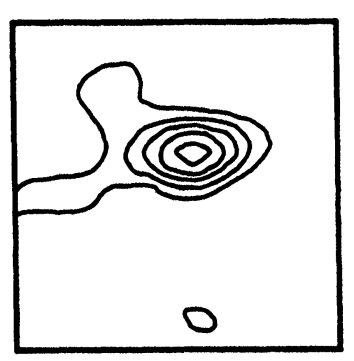

$71.6^{\circ}$

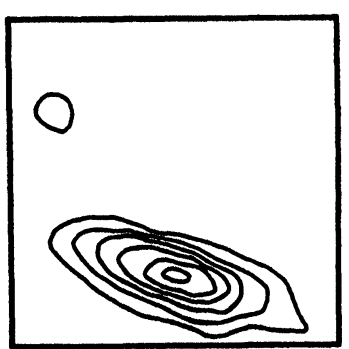

$21.6^{\circ}$

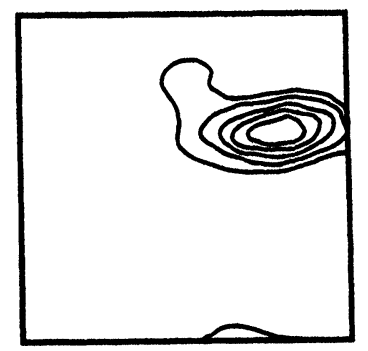

$51.3^{\circ}$

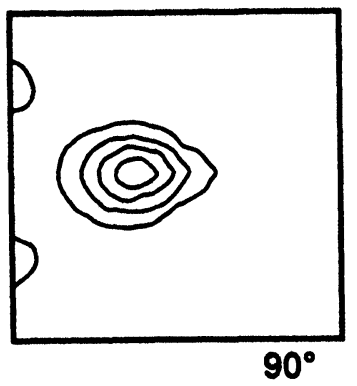

Figure 4 (a) ODF of the Fe-30\% Ni austenite cold rolled $90 \%$. Contour intervals, $2 \times$ random; MFH $=12.7$.

by Davies and Bateman (1981) for transformation texture prediction. The latter authors found that the first hypothesis led to positive results but that the intensities were somewhat weak. Liu and Bunge (1991), working on a strong cube textured $\mathrm{Fe}-30 \% \mathrm{Ni}$ alloy and using the Nishiyama-Wassermann orientation relationship, observed that the most favoured variants were those associated with the $\langle 110\rangle$ slip directions that were most active during prior deformation of the austenite. They also indicated, however, that the austenite slip plane involved in the orientation relation $\left(\{111\}_{\gamma} / /\{110\}_{\alpha}\right)$ was clearly not the most active plane. Support for the latter mechanism was obtained experimentally in several materials (Olsen and Jesser, 1971a and b; Stone and Thomas, 1974) and 

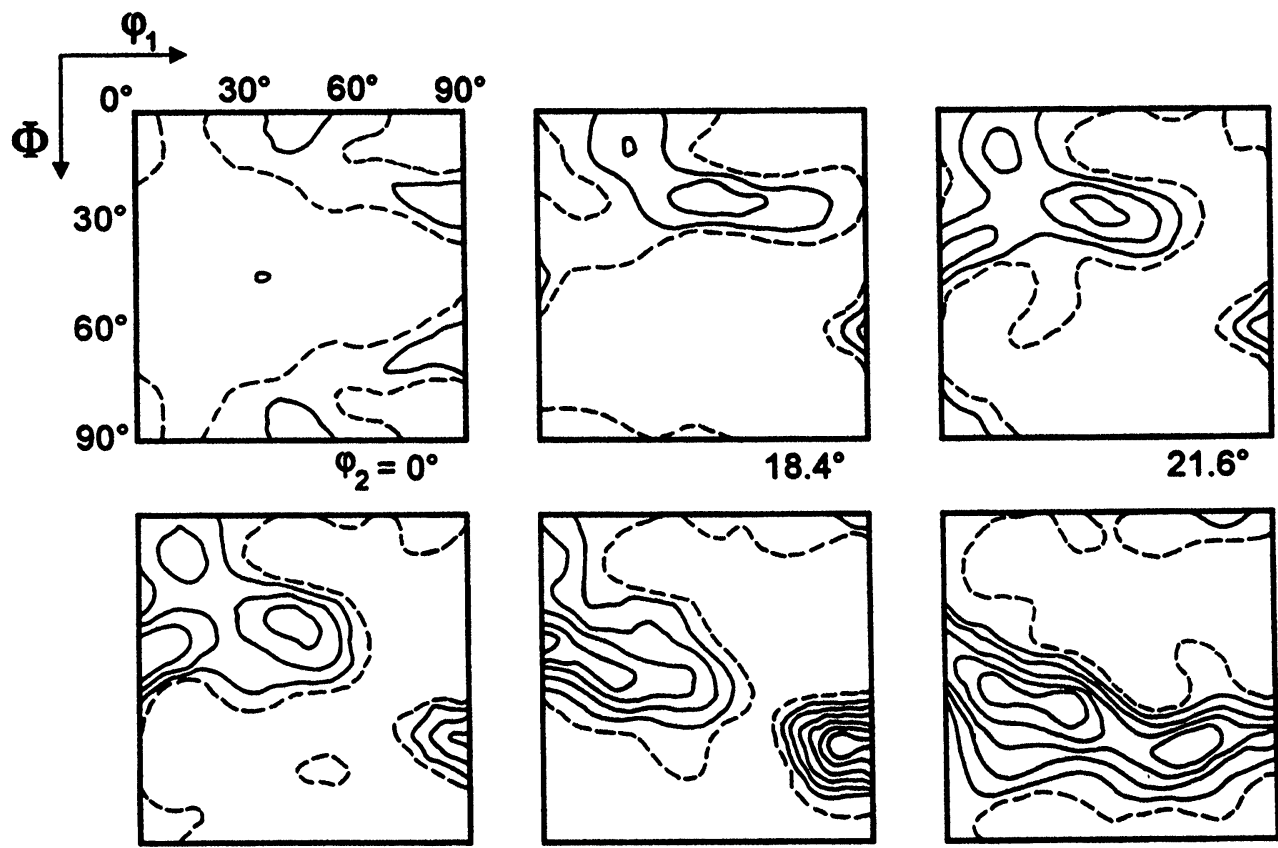

$31.7^{\circ}$

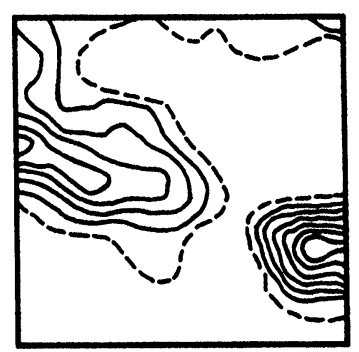

$45^{\circ}$

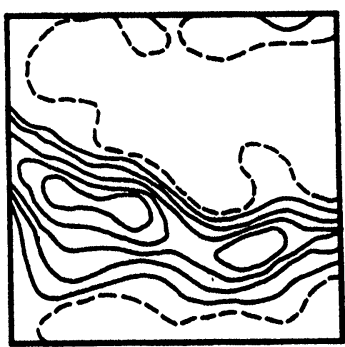

$51.3^{\circ}$

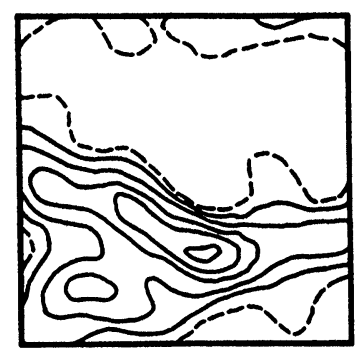

$63.4^{\circ}$

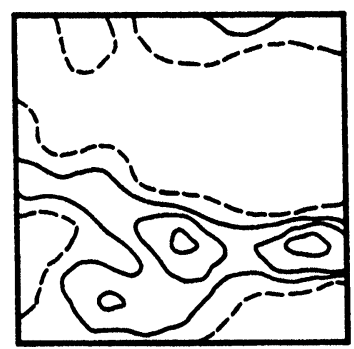

$71.6^{\circ}$

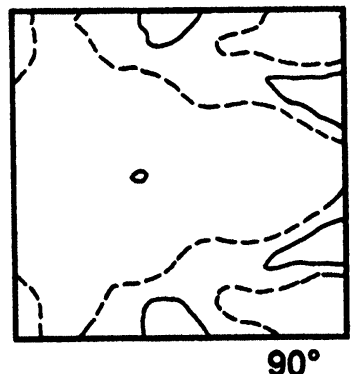

Figure 4 (b) Martensite texture produced by transformation of the material in Figure 4a. Contour intervals, $1 \mathrm{x}$ random; $\mathrm{MFH}=6.9$. After Bateman and Davies (1981); replotted according to the Bunge notation.

used to account for specific features of the fcc-to-bcc (or bct) transformation (Olsen and Jesser, 1971b).

In the present version of the model, the variant selection rule relies quite simply on the sign of the transformation work. It is assumed that the energy stored in the matrix is released during transformation and favours the growth of a given nucleus as long as the sign condition is satisfied. This seems to simulate more accurately the high dislocation density type of martensite formation than the twinning type since closer agreement is observed between the predicted and $\mathrm{Nb}$ steel textures than between the former and that of the $\mathrm{Fe}-30 \% \mathrm{Ni}$ alloy. 

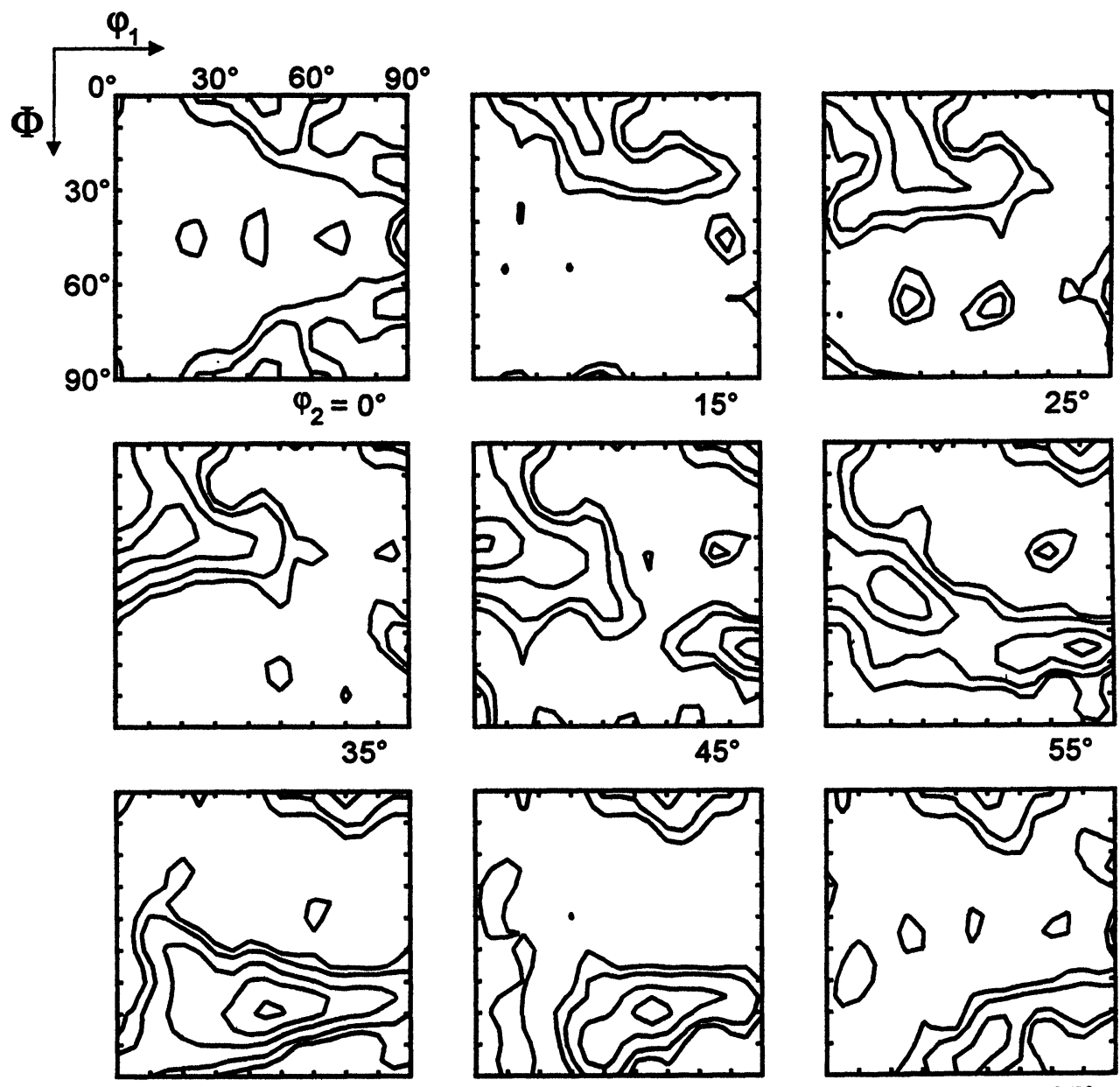

Figure 5 Experimental texture of the $\mathrm{Nb}$ microalloyed steel. Levels: 1, 2, 4, 6, and 8 times random. $\mathrm{MFH}=8.4$.

The present criterion can, nevertheless, be improved by weighting the selected variant in proportion to the magnitude of the transformation work, i.e. of the energy released. It is also possible to define a critical energy value that must be exceeded before a particular variant will form. Such a condition corresponds to a critical residual stress criterion, since the transformation strains are fixed by the lattice geometries of the two phases. These modifications can be used to improve the predictive accuracy when the model is applied to the twinning type of transformation. Such calculations are currently in progress and the results obtained by this means will be described in a forthcoming publication. 
Table 1 ODF intensities for important orientations in the predicted and experimental textures.

\begin{tabular}{lccc}
\hline Orientation & Predicted texture & $\begin{array}{c}\text { ODF Intensities } \\
\text { Nb microalloyed } \\
\text { steel (Butrón- } \\
\text { Guillén, 1995) }\end{array}$ & $\begin{array}{c}\text { Fe-30\%Ni alloy } \\
\text { (Bateman and } \\
\text { Davies, 1981) }\end{array}$ \\
\hline$(001)[1 \overline{1} 0]$ & 5.2 & 5.0 & 2.4 \\
$(012)[0 \overline{2} 1]$ & 3.4 & 3.2 & 1.6 \\
$(113)[1 \overline{1} 0]$ & 3.1 & 6.3 & 3.3 \\
$(332)[11 \overline{3}]$ & 5.8 & 7.7 & 2.7 \\
$(211)[11 \overline{3}]$ & 4.4 & 5.2 & 3.0 \\
MFH & 6.9 & 8.4 & 6.9 \\
\hline
\end{tabular}

\section{SUMMARY}

A model was presented for the prediction of austenite transformation textures. The model uses a two-step variant selection criterion that relies on: i) a slip system based variant selection rule to limit the number of the possible bcc nucleus orientations (12 or 16 out of 24); and ii) a requirement that the residual stress in the matrix be reduced, which further eliminates a number of applicable K-S variants. The martensite texture predicted in this way agreed very well with experimental data from an $\mathrm{Fe}-30 \% \mathrm{Ni}$ alloy and a $\mathrm{Nb}$ microalloyed steel. The closer agreement with the steel texture seems to indicate that, in its present form, the model is better suited to predicting the textures associated with the lath type of martensite in which the transformation strains are accommodated by dislocation substructures. A modification is suggested that is expected to improve the accuracy when the model is applied to the shear type of transformation that takes place in $\mathrm{Fe}-30 \% \mathrm{Ni}$ alloys.

\section{Acknowledgements}

CSdaCV is indebted to the Conselho Nacional de Desenvolvimento Cientifíco e Tecnológico (Brazilian National Science and Technology Council) - CNPq and to the Brazilian Army - EB for financial support. MPBG and JJJ express their gratitude to the Natural Sciences and Engineering Research Council of Canada (NSERC) and the Canadian Steel Industry Research Association (CSIRA) for grants in aid of this research.

\section{References}

Bateman, R. M. and Davies, G. J. (1981). The inheritance of texture on transformation from austenite to martensite in an Fe-30\%Ni alloy. In Proc. 6th. Int. Conf. on Textures of Materials, vol. 1, pp. 690-702, Tokyo, The Iron and Steel Institute of Japan.

Bishop, J. F. and Hill, R. (1951). A theory of the plastic distortion of a polycrystalline aggregate under combined stresses. Phil. Mag., vol. 42, pp. 414-427. A theoretical derivation of the plastic properties of a polycrystalline face-centred metal. Phil. Mag., vol. 42, 1298-1307.

Butrón-Guillén, M. P. (1995). Transformation textures in hot rolled steels. Ph.D. Thesis, McGill University, Montreal, Canada.

Davies, G. J., Kallend, J. S. and Ruberg, T. (1973). In Deformation and recrystallization textures in metals and their industrial applications, Soc. Franç. Métall., Nancy, p. 299. 
Davies, G. J., Kallend, J. S. and Morris, P. P. (1976). The quantitative prediction of transformation textures. Acta Met., vol. 24, pp. 159-172.

Davies, G. J. and Bateman, R. M. (1981). The influence of variant selection in the inheritance of texture during phase transformations. Proc. 6th. Int. Conf. on Textures of Materials, vol. 1, pp. 132-148, Tokyo, The Iron and Steel Institute of Japan.

Haslam, K., Coleman, T., Dulieu, D. and Dillamore, I. L. (1973). Texture formation in the rolling of steel plate. In Deformation and recrystallization textures in metals and their industrial applications, Soc. Franç. Métall., Nancy, p. 369-381.

Honeycombe, R. W. K. (1981). Steels: Microstructure and Properties, Edward Arnold, London.

Inagaki, H. (1981). Transformation textures in steel. Proc. 6th. Int. Conf. on Textures of Materials, vol. 1, p. 149-163, Tokyo, The Iron and Steel Institute of Japan.

Jones, A. and Walker, B. (1974). The structural state of austenite during continuous hot strip mill rolling. Met. Sci., vol. 8, pp. 397-406.

Kallend, J. S. and Davies, G. J. (1972). A simulation of texture development in F.C.C. metals. Phil. Mag., vol. 25 , p. $471-490$.

King, A. D. and Bell, T. (1975). Crystallography of grain boundary proeutectoid ferrite. Met. Trans. $A$, vol. 6A, pp. $1419-1429$.

Kurdjumov, G. and Sachs, G. (1930). Über den mechanismus det stahlhärtung. Z. Phys., vol. 64, pp. 325-343.

Liu, W. P. and Bunge, H. J. (1991). Variant selection in the martensitic transformation of an $\mathrm{Fe}-$ $30 \% \mathrm{Ni}$ alloy with cube texture. Materials Letters, vol. 10, No. 7.8 , pp. 336-343.

McDougall, P. G. and Wayman, C. M. (1992). The crystallography and morphology of ferrous martensites. In Martensite: A Tribute to Morris Cohen, edited by G. B. Olson and W. S. Owen, ASM International.

Miyaji, H. and Furubayashi, E. (1990). Effect of specimen size on the variant selection in martensitic transformation. Text. and Microst., vol. 12, pp. 189-197.

Nishiyama, Z. (1936). On the transformation Gamma-Alpha of stainless Invar caused by stress and the mechanism of the transformation. Sci. Rep. Tohoku Imperial University, vol. 25, pp. 94-103.

Olsen, G. H. and Jesser, W. A. (1971a). The fcc-bcc transformation in iron deposits on copper. Acta Metall., vol. 19, pp. 1009-1014.

Olsen, G. H. and Jesser, W. A. (1971b). The effect of applied stress on the fcc-bcc transformation in thin iron films. Acta Metall., vol. 19, pp. 1299-1302.

Ray, R. K. and Jonas, J. J. (1990). Transformation textures in steels. Int. Mat. Rev., vol. 35, No. 1 , pp. 1-36.

Ray, R. K., Jonas, J. J., Butron-Guillén, M. P. and Savoie, J. (1994). Transformation textures in steels. ISIJ International, vol. 34 , No. 12 , pp. 927-942.

Roe, R. J. (1965). Description of crystallite orientation in polycrystalline materials. III. General solution to pole figure inversion. J. App. Phys., vol. 36, pp. 2024-2031.

Sandvik, B. P. J. and Wayman, C. M. (1983). Characteristics of lath martensite: Part I. Crystallographic and substructure features. Met. Trans. A, vol. 14A, pp. 809-822.

Sargent, C. M. (1974). Texture transformations. Scr. Met., vol. 8, pp. 821-824.

Savoie, J., Ray, R. K., Butrón-Guillén, M. P. and Jonas, J. J. (1993). Comparison between simulated and experimental transformation textures in a $\mathrm{Nb}$ microalloyed steel. Acta Metall. Mater., vol. 42, pp. 2511-2523.

Stone, G. and Thomas, G. (1974). Deformation induced alpha and epsilon martensites in Fe-Ni-Cr single crystals. Met. Trans., vol. 5, pp. 2095-2102.

Wassermann, G. (1933). Einflu $\beta$ der $\alpha$ - $\psi$-umwandlung eines irreversiblen Nickelstahls auf krystallorientierung und zugfestigkeit. Archiv für das Eisenhüttenwesen, vol. 6, pp. 347-351.

Yutori, T. and Ogawa, R. (1981). Proc. 6th. Int. Conf. on Textures of Materials, vol. 1, p. 669, Tokyo, The Iron and Steel Inst. of Japan. 